employment the occupational medical officer should also be notified.

Few diabetics register on the Disabled Persons Register, but those with disabling complications may find it advantageous to do so and to seek the advice of their local disablement resettlement officer.

The present positive attitude towards the management of diabetes has ensured that most diabetics can be usefully and suitably employed, but the satisfactory care of the diabetic employee does require efficient medical support with good cooperation between the diabetic clinic, the family physician, and the occupational health service.

Consultant Physician,

JOHN LISTER

East Berkshire Health District,

Windsor SL4 $3 \mathrm{HH}$

${ }^{1}$ Lister J. The employment of diabetics. Fournal of Social and Occupational Medicine 1982;32:153-8.

${ }^{2}$ Jackson JGL. British Diabetic Association employment survey. London: British Diabetic Association, 1961.

3 Frier BM, Steel JM, Matthews DM, Steel JM, Duncan LJP. Driving and insulin-dependent diabetes. Lancet $1980 ; \mathrm{i}: 1232-4$.

4 Mastbaum L, Tetrick I, Alexander RW. Physician's guidelines for employment and placement of the diabetic in industry-an update. $\mathscr{f} O M$ $1980 ; 22: 601-2$.

${ }^{5}$ Soskin S. Diabetes-its relation to industry. Industrial Medicine and Surgery $1954 ; 23: 106-7$.

\section{Thrombosis, abortion, cerebral disease, and the lupus anticoagulant}

Systemic lupus erythematosus, with its broad range of clinical and immunological abnormalities, continues to provide lessons relevant to research in a wider variety of disciplines and diseases. In some patients three apparently unrelated clinical features of systemic lupus erythematosus-recurrent venous thrombosis, central nervous system disease (including myelitis), and recurrent abortions-may, it seems, have common pathogenic mechanisms. Clinicians have suspected as much for some time-those dealing with many patients with systemic lupus erythematosus recognise a group of women who have as features of their disease multiple (even a dozen or more) spontaneous abortions, multiple deep vein and other thromboses, and neurological abnormalities including either putative cerebral thrombosis or myelitis or both. Interestingly, some of these patients have negative test results for antinuclear antibody. ${ }^{1}$

The serological abnormality common to some (but not all) of these patients is a circulating anticardiolipin antibody responsible for the positive Wassermann reaction or so called false positive serological test for syphilis. Over 25 years ago Laurell and Nilsson ${ }^{2}$ recognised that patients with systemic lupus erythematosus with biological false positive Wassermann reactions also had a high incidence of another "antilipid" antibody - the so called "lupus anticoagulant." This antibody, now known to be present in conditions other than systemic lupus erythematosus, appears to act by interfering with the binding of phospholipid to form prothrombin activator, thereby affecting both the intrinsic and extrinsic clotting pathways. ${ }^{3}$ Though in laboratory tests the lupus anticoagulant slightly prolongs the partial thromboplastin time, the seeming paradox is that its presence in a patient's circulation appears to be associated not with bleeding but with a tendency to thrombosis. ${ }^{4-9}$

Mueh et al reviewed 35 patients whose plasma possessed lupus anticoagulant activity. Six of these patients had systemic lupus erythematosus, and 24 had autoimmune abnormalities. ${ }^{8}$ Six of 28 patients had a positive Venereal Disease Research Laboratory test result. Eleven of the 35 patients suffered one or more thrombotic episodes, including cerebral thrombosis. Six of the patients had thrombocytopenia (possibly due to antibody activity against phospholipid antigen in the platelet membrane).

Another clinical association subsequently observed in association with the lupus anticoagulant is recurrent spontaneous abortion..$^{5}$ One mechanism for this was suggested by Carreras et $a l,{ }^{7}$ who studied a patient with recurrent arterial thrombosis and intrauterine fetal death. The IgG fraction of her serum containing lupus anticoagulant was found to inhibit the production of prostacyclin $\left(\mathrm{PGI}_{2}\right)$ by rat aorta and pregnant myometrium. They speculated that by its effect on phospholipids the lupus anticoagulant might interfere with the release of arachidonic acid from the cell membranes.

Recent studies from the Hammersmith Hospital have confirmed and extended the association of the lupus anticoagulant with thrombosis. Boey et al studied 31 patients with systemic lupus erythematosus and other connective tissue diseases whose plasma showed lupus anticoagulant activity. ${ }^{9}$ Thrombotic episodes such as deep vein thrombosis, pulmonary embolism, cerebral thrombosis, and axillary vein thrombosis were recorded in 18 of the 31 . Of the 26 women with lupus anticoagulant activity, nine gave a history of one or more abortions. Seven of the 31 patients had positive Venereal Disease Research Laboratory test results. Asherson et $a l^{10}$ from the same unit reported six patients with systemic lupus erythematosus and pulmonary hypertension, five of whom had lupus anticoagulant activity - a finding that stimulates speculation on a possible wider role of lupus anticoagulant in "idiopathic" pulmonary hypertension, where serological abnormalities including false positive serological tests for syphilis have been previously observed, and where intrapulmonary venous thrombosis may be a contributing factor. Further interesting anecdotal observations from these studies were the association of antinuclear antibody negative discoid lupus erythematosus with the lupus anticoagulant and pulmonary hypertension ${ }^{10}$ and the association of the lupus anticoagulant with "idiopathic" portal hypertension in one patient and with renal vein thrombosis in two others.

Elegant studies supporting the concept that some antibodies may cross react with complex lipid antigens have been reported by Stollar, Schwartz, and others, who showed that monoclonal anti-DNA antibodies, raised from lupus mice, may bind a variety of polynucleotides and phospholipids. ${ }^{11-13}$ One such antibody also had lupus anticoagulant activity. In such antibodies the antigenic determinants appeared to be the phosphodiester linked phosphate group present in some phospholipids, including cardiolipin, as well as in the sugar phosphate backbone of polynucleotides such as DNA. ${ }^{11-13}$ Certain restricted groups of lymphocytes may produce antibodies with idiotypic diversity. Of interest is the report that immunisation of normal rabbits or mice with cardiolipin stimulates the production of both anticardiolipin and antiDNA antibodies. ${ }^{13}$

These laboratory studies when taken with their clinical counterparts suggest that these antibodies may have pathogenic importance. By implication, therefore, their removal by immunosuppression, plasmapheresis, or (one day) by the use 
of anti-idiotypes might be expected to have therapeutic value. Observations in our unit (unpublished) have shown that in certain circumstances immunosuppression does result in disappearance of the lupus anticoagulant. Furthermore, Lubbe et al recently reported successful pregnancies in five patients who had previously had spontaneous abortions and whose lupus anticoagulant disappeared on immunosuppressive treatment. ${ }^{14}$

Of even wider clinical interest is the possibility that such antibodies may react with complex brain lipids such as sphingomyelin. Clinical studies have hinted that the cerebral features of systemic lupus erythematosus may be associated with the presence of this family of antibodies. To study this possibility, the assays used to detect antilipid antibodies would need to be refined; so both clinical and research interest has been stimulated by the recent study by Harris et al, who have developed a sensitive solid phase radioimmunoassay for anticardiolipin antibodies some 200-400 times more sensitive than, for example, the precipitation method used in the Venereal Disease Research Laboratory test. ${ }^{15}$ There was a strong correlation between raised titres of anticardiolipin antibodies and venous and arterial thrombosis. Of the 15 patients with the highest anticardiolipin antibody titres, six had a history of venous thrombosis and five had cerebral thrombosis without other predisposing factors. Two each had pulmonary hypertension and multiple abortions.

This simple immunoassay appears to have predictive value for thrombosis in systemic lupus erythematosus and related disorders. Harris et al also found high titres of anticardiolipin and antisphingomyelin antibodies in a patient with transverse myelitis and a false positive Veneral Disease Research Laboratory test result. This disease had features similar to the endemic Jamaican disease "Jamaican neuropathy"-a meningomyelitis in which similar abnormalities have been seen. ${ }^{16} 17$

Spreading the net even further, they reported high titre anticardiolipin antibody values in a patient with Rehçet's disease-a syndrome characterised by thrombosis and features of central nervous system disease including myelopathy. The potential implications of research into antibodies such as anticardiolifin and antisphingomyelin antibodies are obvious, with clinical applications in other diseases where thrombosis or demyelination occur.

These antibodies may, of course, be epiphenomenafellow travellers with little or no pathogenic importance. That seems unlikely. Though the results of the immunological analysis are always open to dispute and the association with neurological disease is still speculative, the clinical association with thrombotic disease appears strong.

For those of us hardened into nihilism by years of study of various autoantibodies in systemic lupus erythematosus, there is a rare sense of excitement at the implications of the associations now being reported.

\section{GRAHAM R V HUGHES}

Consultant Physician,

Hammersmith Hospital

London W12 0HS

${ }^{1}$ Colaco $\mathrm{CH}$, Elkon KB, Gharavi AE, Hughes GRV. The lupus anticoagulant: clinical and laboratory associations. (Abstract.) Ann Rheum Dis $1983 ; 42: 228$.

${ }^{2}$ Laurell B-B, Nilsson IM. Hypergammaglobulinemia, circulating anticoagulant, and biologic false positive Wassermann reaction. $f$ Lab Clin Med 1957;49:694-707.

${ }^{3}$ Byron MA. The clotting defect in SLE. Clin Rheum Dis 1982;8:137-51.

4 Bowie EJW, Thompson JH Jr, Pascuzzi CA, Owen CA Jr. Fhrombosis in systemic lupus erythematosus despite circulating anticoagulants. f Lab Clin Med 1963;62:416-30.
${ }^{5}$ Firkin BG, Howard MA, Radford N. Possible relationship between lupus inhibitor and recurrent abortion in young women. Lancet 1980;ii:366.

${ }^{6}$ Manoharan A, Gibson L, Rush B, Feery BJ. Recurrent venous thrombosis with a "lupus" coagulation inhibitor in the absence of systemic lupus. Aust NZ 7 Med 1977;7:422-6.

${ }^{7}$ Carreras LO, Defreyn G, Machins SJ, et al. Arterial thrombosis, intrauterine death and "lupus" anticoagulant: detection of immunoglobulin interfering with prostacyclin formation. Lancet 1981;i:244-6.

${ }^{8}$ Mueh JR, Herbst KD, Rapaport SI. Thrombosis in patients with the lupus anticoagulant. Ann Intern Med 1980;92:156-9.

${ }^{9}$ Boey ML, Colaco CB, Gharavi AE, Elkon KB, Loizou S, Hughes GRV. Thrombosis in SLE: striking association with the presence of circulating lupus anticoagulant. $\mathrm{Br} \mathrm{Med} \mathcal{F} 1983 ; 287: 1021-3$.

${ }^{10}$ Asherson RA, Mackworth-Young CG, Boey ML, et al. Pulmonary hypertension in systemic lupus erythematosus. $\mathrm{Br} \mathrm{Med} \mathcal{F} 1983 ; 287$ : 1024-5.

11 Lafer EM, Rauch J, Andrzejewski C Jr, et al. Polyspecific monoclonal lupus autoantibodies reactive with both polynucleotides and phospholipids. F Exp Med $1981 ; 153: 897-909$.

${ }^{12}$ Shoenfeld Y, Rauch J, Massicotte H, et al. Polyspecificity of monoclonal lupus autoantibodies produced by human-human hybridomas. $N$ Engl f Med 1982;308:414-20.

${ }^{13}$ Schwartz RS. Monoclonal lupus autoantibodies. Immunology Today $1983 ; 4: 68-9$.

${ }^{14}$ Lubbe WF, Butler WS, Palmer SJ, Liggins GC. Fetal survival after prednisone suppression of maternal lupus-anticoagulant. Lancet $1983 ; \mathrm{i}: 1461-2$.

15 Harris EN, Gharavi AE, Boey ML, et al. Anticardiolipin antibodies: detection by radioimmunoassay and association with thrombosis in SLE. Lancet (in press).

${ }^{16}$ Wilson WA, Hughes GRV. Aetiology of Jamaican neuropathy. Lancet $1975 ; \mathrm{i}: 345$.

17 Hughes GRV. Central nervous system lupus-diagnosis and treatment. f Rheumatol 1980;7:405-11.

\section{Malaria vaccination: two steps forward, one backward}

In the two years since the topic of malaria vaccination was last reviewed in the $B M \mathcal{F}^{1}$ important technical advances have been made in the search for antigens that can induce a protective response against the various stages of the malaria parasite. The pertinent question is whether, or to what degree, these advances bring us closer to the manufacture and practical deployment of a vaccine to protect people against this disease.

Without question multiple drug resistance in the malignant tertian parasite, Plasmodium falciparum, is spreading alarmingly across the eastern parts of the African continent and Madagascar. Resistance is also extending westwards across India and eastwards as far as malaria goes in the south west Pacific. The endemic areas of Latin America, too, have faced this problem for many years. Radically new antimalarial drugs are most unlikely to become available in the short term, especially for prophylaxis. Reports on mefloquine, a potent, synthetic analogue of quinine, are already throwing up hints that parasites can become resistant to it, even though the drug is still only in the stage of clinical trial. Artemisinine (Qinghaosu), the new derivative of an ancient Chinese herbal remedy, is at an early stage of its development and looks likely to lend itself only to therapeutic and not to prophylactic use. Other new drugs such as halofantrine (in a sense an analogue of mefloquine) and a new series of quinones which are the subject of patent applications by the Wellcome Foundation will need at least five more years of investigation before they could be widely applied even if they overcome all the hurdles of new drug development. No new insecticides are on the horizon that are both technically superior to DDT and economically deployable by most Third World countries. Inevitably, therefore, great hopes are being pinned on the malaria vaccines as 